\title{
Photosynthetic Photon Flux, Photoperiod, and Temperature Effects on Emissions of (Z)-3-hexenal, $(Z)$ - 3-hexenol, and (Z)-3-hexenyl Acetate from Lettuce
}

\author{
Craig S. Charron ${ }^{1}$ and Daniel J. Cantliffe ${ }^{2}$ \\ Horticultural Sciences Department, University of Florida, Gainesville, FL 32611 \\ Raymond M. Wheeler ${ }^{3}$ \\ National Aeronautics and Space Administration, Mail Code MD-RES, Kennedy Space Center, FL 32899
}

\author{
Ara Manukian ${ }^{4}$ and Robert R. Heath ${ }^{5}$ \\ U.S. Department of Agriculture, Agricultural Research Service, Gainesville, FL 32604
}

Additional index words. controlled environments

\begin{abstract}
To investigate the effects of environment on plant volatile emissions, 'Waldmann's Green' leaf lettuce was cultivated under different levels of photosynthetic photon flux (PPF), photoperiod, and temperature. A modified growth chamber was used to sample plant volatile emissions nondestructively, over time, and under controlled conditions. Total volatile emission rates were significantly higher from lettuce cultivated under PPF of $360 \mathrm{or} 200 \mu \mathrm{mol} \cdot \mathrm{m}^{-2} \cdot \mathrm{s}^{-1} \mathrm{compared}$ to $105 \mu \mathrm{mol} \cdot \mathrm{m}^{-2} \cdot \mathrm{s}^{-1}$, and significantly higher under a 16-h photoperiod than an 8-h photoperiod. No differences were detected among emission rates from different temperature treatments. In controlled environments, emissions could be regulated by adjusting environmental conditions accordingly.
\end{abstract}

In a closed plant cultivation environment such as that of the controlled ecological life support system (CELSS) under development by the National Aeronautics and Space Administration (NASA), the emission of volatile compounds by plants may require toxin management strategies. Qualitative and quantitative measurements of volatile emissions from candidate crops are necessary, as are assessments of their overall impact on the functioning of CELSS. In a CELSS, plants are produced under controlled light and temperature. Consequently, it is important to evaluate how such environmental variables affect plant volatile emissions.

(Z)-3-hexenal, (Z)-3-hexenol, and (Z)-3-hexenyl acetate emissions were detected from hydroponic 'Waldmann's Green' leaf lettuce (Lactuca sativa L.) at the beginning of the dark period of a diurnal cycle (Charron et al., 1996). (Z)-3-hexenal has been identified as a volatile emission product from mechanically damaged plants (Buttery, 1981; Buttery and Ling, 1993). (Z)-3-hexenol and (Z)-3-hexenyl acetate emissions have been measured from many agricultural crops (Arey et al., 1991) and from natural species, such as trees of Northern Hemisphere forests (Isidorov et al., 1985). In a survey of volatile emissions from vegetation in California's Central Valley, the ratios of monoterpenes to one another were generally constant. In contrast, the ratios of monoterpenes to oxygenated hydrocarbons, especially (Z)-3-hexenyl acetate, seemed to vary randomly. The investigators suggested that the emissions of (Z)-3-hexenol and (Z)-3-hexenyl acetate were not

\footnotetext{
Received for publication 24 Mar. 1995. Accepted for publication 7 Nov. 1995. Univ. of Florida journal series no. R-04133. We gratefully acknowledge the technical assistance of B.D. Dueben and A.T. Proveaux. The cost of publishing this paper was defrayed in part by the payment of page charges. Under postal regulations, this paper therefore must be hereby marked advertisement solely to indicate this fact.

${ }^{1}$ Predoctorate fellow.

${ }^{2}$ Professor and chair.

${ }^{3}$ Plant physiologist.

${ }^{4}$ Systems engineer.

${ }^{5}$ Research chemist.
}

controlled by temperature, but noted that additional research was necessary (Winer et al., 1992).

The purpose of the present investigation was to determine qualitatively and quantitatively how volatile emissions from 'Waldmann's Green' leaf lettuce are influenced when the lettuce is cultivated under different levels of photosynthetic photon flux (PPF), photoperiod, and temperature.

\section{Materials and Methods}

\section{Measuring volatiles}

Volatiles produced by lettuce were measured in a modified growth chamber (model EF7; Controlled Environments) equipped with a hydroponic system (Charron et al., 1996).

Plant material and cultural conditions. 'Waldmann's Green' leaf lettuce seeds were prepared in germination boxes as described previously (Charron et al., 1996). A separate germination box was prepared on each of 4 consecutive days. At the completion of their respective germination intervals, one seedling from each box was transplanted into a hydroponic tray.

Environmental conditions. PPF, photoperiod, and temperature were the same during germination and when the seedlings were transplanted into the hydroponic trays. Seven days were required to produce seedlings of sufficient size for transplanting, except for the 8 -h photoperiod treatment when an additional $48 \mathrm{~h}$ was required.

Experimental design. A split-block experimental design was used with PPF, photoperiod, or temperature as the main blocks and time (7-day intervals) as split plots with four replications within the growth chamber. Two of the following conditions were held constant in any one experiment: PPF, photoperiod, or temperature. The remaining factor was varied at three levels (Table 1).

Sampling procedures. Pyrex cylindrical mold-blown glass jars were used as sampling vessels (Charron et al., 1996). Air samples from the jar flowed through a volatile collector trap containing 30 $\mathrm{mg}$ of Super-Q adsorbent (Altech, Deerfield, Ill.) at 1.5 liters $\cdot \mathrm{min}^{-1}$.

Plants were generally sampled at 7-day intervals and at the day 
of harvest, determined when the plants' leaves were near to the glass of the sampling jar. For each experiment, volatiles were collected on a minimum of 3 sampling days. To achieve this before the plant outgrew the sampling jar, a 3- or 4-day interval between harvest and the previous sampling day was sometimes used.

Before sampling, cooled, purified air was used to purge the glass collection jar until the temperature inside the jar was $\pm 1.5 \mathrm{C}$ of the growth chamber setpoint temperature. An inlet airflow of 15.5 liters $\cdot \mathrm{min}^{-1}$ was sufficient for all experiments except the highand low-temperature treatments (28/23C and 18/13C). To adjust for these temperatures, the inlet airflows were set at 12.0 and 18.1 liters $\cdot \mathrm{min}^{-1}$, respectively.

After purging, the jar was placed over the plant $1.5 \mathrm{~h}$ before the onset of the dark period and left in place without sampling for $1 \mathrm{~h}$. Subsequently, volatiles were collected at 0.5 -h intervals beginning $0.5 \mathrm{~h}$ before the dark period and ending $1.5 \mathrm{~h}$ later, except for the first experiment conducted $\left(360 \mu \mathrm{mol} \cdot \mathrm{m}^{-2} \cdot \mathrm{s}^{-1} \mathrm{PPF}\right.$; $16-\mathrm{h}$ photoperiod; $23 / 18 \mathrm{C}$ ) when sampling began $2 \mathrm{~h}$ before the dark period and ended $6 \mathrm{~h}$ later. The determination that volatiles were emitted only within the 0.5 -h period after the dark period began made the longer sampling periods unnecessary.

Volatile collector traps were eluted and samples were analyzed by capillary gas chromatography (Charron et al., 1996).

Constant temperature study. In each treatment, the growth chamber temperature decreased 5 C over the first 30 min of the dark cycle. To test how constant temperature in the sampling jar would affect lettuce volatile emissions at the light-dark transition, the copper coil through which the inlet air passed before entering the sampling jar was submersed in about $70 \mathrm{C}$ water. This was done at a light temperature of $18 \mathrm{C}$ and a dark temperature of $13 \mathrm{C}$. By adjusting the level of the water, the temperature within the jar was maintained at $18 \pm 1.5 \mathrm{C}$ after the dark period began. Volatile s were collected as described above, and replicated on three plants at 39 days after transplanting (DAT).

Constant light study. In a separate experiment, one lettuce plant that had been cultivated at $23 \mathrm{C}$ during the 16 -h light period and $18 \mathrm{C}$ during the 8 -h dark period was exposed to light continuously for $72 \mathrm{~h}$ beginning at 32 DAT. Air was sampled daily for $6 \mathrm{~h}$ beginning at the time $2 \mathrm{~h}$ before the dark period had previously begun.

Volatiles emitted by damaged lettuce. Volatiles released by damaged lettuce were collected from plants grown under a PPF of $200 \mu \mathrm{mol} \cdot \mathrm{m}^{-2} \cdot \mathrm{s}^{-1}, 16-\mathrm{h}$ photoperiod, and light-dark temperatures of 23 and $18 \mathrm{C}$, respectively. Lettuce was shaken for $30 \mathrm{sec}$ by a metal rod inserted through a port in the glass sampling jar. Some tearing of the lettuce leaves occurred. Volatile collections were conducted during the light and dark periods beginning immediately after damage was inflicted.

\section{Measuring biomass}

Biomass data were collected to calculate volatile emission rates on a shoot dry weight basis.

Growth chamber comparison. The destructive sampling necessary for biomass measurements was incompatible with measuring volatiles from plants over time. Growth rate experiments were conducted in a model E15 growth chamber (Controlled Environments) and the EF7 chamber to test the feasibility of using biomass data from chamber E15 for calculating volatile emission rates on a dry weight basis. In the E15 growth chamber, a 6.4-mm acrylic barrier was positioned beneath a light bank consisting of 52-W incandescent bulbs (input wattage 17\%) and 160-W cool-white fluorescent (input wattage 83\%) lamps. Conditions in the EF7 and E15 growth chambers were maintained at $360 \mu \mathrm{mol} \cdot \mathrm{m}^{-2} \cdot \mathrm{s}^{-1} \mathrm{PPF}$, 16-h photoperiod, and light-dark temperatures of 23 and $18 \mathrm{C}$, respectively.

The hydroponic plant-growing system in the E15 chamber used an acrylic tray $149 \mathrm{~cm}$ long $\times 20 \mathrm{~cm}$ wide $\times 3.8 \mathrm{~cm}$ deep. An acrylic lid containing thirty-six $1.9-\mathrm{cm}$ holes separated by $7.6-\mathrm{cm}$ centers covered the tray. The nutrient solution composition, $\mathrm{pH}$, temperature, flow rate, and depth in the tray were the same as those in the EF7 chamber. A water bath (model RS-20; Brinkman) maintained the nutrient solution temperature by controlling the temperature of a stainless-steel coil submersed in the reservoir.

An acrylic germination box was constructed to accommodate more seeds than in the germination boxes used for seedlings grown for the EF7 chamber. The bottom box measured 14.0-cm wide $x$ $50.8-\mathrm{cm}$ long $\times 5.7-\mathrm{cm}$ deep and was covered with an acrylic lid with three $3-\mathrm{mm}$ slits separated by $3.8 \mathrm{~cm}$. The inverted upper box had dimensions of $14.0-\mathrm{cm}$ wide $\times 50.8-\mathrm{cm}$ long $\times 5.7-\mathrm{cm}$ deep. Cultural conditions for germination and transplanting were the same as for lettuce used for volatile sampling. In the E15 chamber, four lettuce plants were removed at 7, 14, 21, 28, and 32 days after transplanting (DAT). Two replications of the experiment were completed. Shoots were measured for dry weight.

To compare the lettuce growth rate in the E15 growth chamber used for biomass determinations to that in the EF7 chamber normally used for volatile collections, 20 seedlings were planted in the EF7 chamber, grown under the same conditions, and harvested at 7, 14, 21, 28, and 32 DAT. Shoot dry weight measurements were obtained. In summary, four or five single plant samples were collected at 7, 14, 21, 28, and 32 DAT for biomass [EF7 (once) and E15 (twice) chambers].

Cultural and environmental conditions. For each of the remaining treatments, biomass data were collected from growth chamber E15. PPF, photoperiod, and temperature in chamber E15 were maintained at the same levels as in chamber EF7. Nutrient solution composition, $\mathrm{pH}$, temperature, flow rate, and depth in the trays were the same as those in the modified growth chamber.

Cultural conditions for germination in chamber E15 were the same as for lettuce used for sampling of volatiles. Lettuce plants were harvested from chamber E15 at times that coincided with sampling times in chamber EF7. Generally, four plants were harvested at a time, and shoot dry weights were measured.

Statistics. Volatile emission rates, expressed on a shoot dry weight basis, were estimated with measurements of volatiles from chamber EF7 and biomass measurements from chamber E15. Asymptotic normality of the emission rates was used to construct a normal-theory procedure for determining confidence limits for mean volatile emission rates (Agresti, 1990; Miller, 1981). For

Table 1. Environmental conditions under which experiments were conducted.

\begin{tabular}{lccc}
\hline \hline $\begin{array}{l}\text { Experimental } \\
\text { variable }\end{array}$ & $\begin{array}{c}\text { Photosynthetic } \\
\text { photon flux }(\mathrm{PPF}) \\
\left(\mu \mathrm{mol} \cdot \mathrm{m}^{-2} \cdot \mathrm{s}^{-1}\right)\end{array}$ & $\begin{array}{c}\text { Photoperiod } \\
(\mathrm{h})\end{array}$ & $\begin{array}{c}\text { Light-dark } \\
\text { temp } \\
(\mathrm{C})\end{array}$ \\
\hline PPF & 360 & 16 & $23 / 18$ \\
& 200 & 16 & $23 / 18$ \\
Photoperiod & 105 & 16 & $23 / 18$ \\
& 360 & 16 & $23 / 18$ \\
Temperature & 360 & 12 & $23 / 18$ \\
& 360 & 8 & $23 / 18$ \\
& 360 & 16 & $28 / 23$ \\
& 360 & 16 & $23 / 18$ \\
& 360 & 16 & $18 / 13$ \\
\hline
\end{tabular}


Table 2. Mean total volatile emission rates $\left(\mu \mathrm{g} \cdot \mathrm{h}^{-1} \cdot \mathrm{g}^{-1}\right)$ sorted by day after transplanting (DAT) and photosynthetic photon flux (PPF) level ${ }^{\mathrm{z}}$.

\begin{tabular}{lccr}
\hline \hline & & PPF $\left(\mu \mathrm{mol} \cdot \mathrm{m}^{-2} \cdot \mathrm{s}^{-1}\right)$ & 105 \\
\cline { 2 - 4 } DAT & 360 & 200 & $0.28 \pm 0.27 \mathrm{bA}$ \\
21 & $3.11 \pm 2.47 \mathrm{a}$ & $1.40 \pm 1.04 \mathrm{a}$ & $0.15 \pm 0.15 \mathrm{bA}$ \\
28 & $1.49 \pm 1.04 \mathrm{a}$ & $2.60 \pm 1.59 \mathrm{a}$ & $0.20 \pm 0.15 \mathrm{bA}$ \\
32 & $1.68 \pm 0.99 \mathrm{a}$ & $1.14 \pm 0.73 \mathrm{a}$ & $0.03 \pm 0.04 \mathrm{~B}$ \\
35 & --- & --- & $0.21 \pm 0.11 \mathrm{~b}$ \\
Mean $^{\mathrm{y}}$ & $2.09 \pm 0.95 \mathrm{a}$ & $1.71 \pm 0.68 \mathrm{a}$ & \\
\hline
\end{tabular}

${ }^{\mathrm{z}}$ Rates $\pm 95 \%$ confidence limits. Experiments conducted under 360 and $200 \mu \mathrm{mol} \cdot \mathrm{m}^{-2} \cdot \mathrm{s}^{-1}$ were terminated at 32 DAT. No volatiles were detected before 21 DAT.

YTreatment mean emission rate for each PPF level.

Tables 2 through 7, means followed by the same lowercase letter within a row or the same uppercase letter within a column are not significantly different at within-group error rate of $\alpha=0.5$. There are no differences in rows without lowercase letters or columns without uppercase letters.

\section{Results}

PPF experiment. No volatiles were detected before 21 DAT at any PPF. Of the three volatile compounds detected, (Z)-3-hexenal, (Z)-3-hexenol, and (Z)-3-hexenyl acetate, no compound predominated over the others under 360 or $200 \mu \mathrm{mol} \cdot \mathrm{m}^{-2} \cdot \mathrm{s}^{-1}$. All three compounds were detected at all sampling times under all levels of $\mathrm{PPF}$, except under $105 \mu \mathrm{mol} \cdot \mathrm{m}^{-2} \cdot \mathrm{s}^{-1}$, when (Z)-3-hexenal was not detected at 35 DAT.

Mean total volatile emission rates (in $\mu \mathrm{g} \cdot \mathrm{h}^{-1} \cdot \mathrm{g}^{-1}$ shoot dry weight) for each PPF level are listed in Table 2. Treatment mean emission rates were calculated as the mean of rates from all sampling days within a treatment when volatiles were detected. Treatment mean emission rates were not different for lettuce grown under $360\left(2.09 \mu \mathrm{g} \cdot \mathrm{h}^{-1} \cdot \mathrm{g}^{-1}\right)$ or $200 \mu \mathrm{mol} \cdot \mathrm{m}^{-2} \cdot \mathrm{s}^{-1}\left(1.71 \mu \mathrm{g} \cdot \mathrm{h}^{-1} \cdot \mathrm{g}^{-1}\right)$, nor were there differences between rates from any two sampling days within either treatment or between the treatments. At 105 $\mu \mathrm{mol} \cdot \mathrm{m}^{-2} \cdot \mathrm{s}^{-1}$, the treatment mean emission rate was $0.21 \mu \mathrm{g} \cdot \mathrm{h}^{-1} \cdot \mathrm{g}^{-1}$ and was significantly different from that at 200 and $360 \mu \mathrm{mol} \cdot \mathrm{m}^{-2} \cdot \mathrm{s}^{-1}$. At 21,28 , and $32 \mathrm{DAT}$, emission rates at $105 \mu \mathrm{mol} \cdot \mathrm{m}^{-2} \cdot \mathrm{s}^{-1}$ were significantly lower than at the same times for lettuce cultivated under either 200 or $360 \mu \mathrm{mol} \cdot \mathrm{m}^{-2} \cdot \mathrm{s}^{-1}$. At $35 \mathrm{DAT}$, the emission rate under $105 \mu \mathrm{mol} \cdot \mathrm{m}^{-2} \cdot \mathrm{s}^{-1}$ was significantly lower than at any of the previous sampling times at the same PPF.

In each volatile collection experiment, lettuce was harvested immediately after the final volatile collections to determine shoot dry weight. For lettuce grown under each PPF level, there were no differences between emission rates determined from measurements of volatiles and biomass from chamber EF7 and those determined from measurements of volatiles and biomass measure- ments taken independently from chambers EF7 and E15 (Table 3). Emission rates at harvest were not different for lettuce grown under 360 and $200 \mu \mathrm{mol} \cdot \mathrm{m}^{-2} \cdot \mathrm{s}^{-1}$, but both were significantly higher than the emission rate at $105 \mu \mathrm{mol} \cdot \mathrm{m}^{-2} \cdot \mathrm{s}^{-1}$.

Regression slopes $\left(b_{1}\right)$ of total volatiles (ng) plotted against time (days) (all data log-transformed) were not different for lettuce grown under 360 and $200 \mu \mathrm{mol} \cdot \mathrm{m}^{-2} \cdot \mathrm{s}^{-1}$. The regression slope obtained under $105 \mu \mathrm{mol} \cdot \mathrm{m}^{-2} \cdot \mathrm{s}^{-1}$ was significantly lower than both slopes obtained at higher PPF levels. The regression slope for total volatiles was significantly higher than that for shoot dry weight at 360 and $200 \mu \mathrm{mol} \cdot \mathrm{m}^{-2} \cdot \mathrm{s}^{-1}$, whereas no differences between volatiles and shoot dry weight regression slopes were detected at 105 $\mu \mathrm{mol} \cdot \mathrm{m}^{-2} \cdot \mathrm{s}^{-1}$.

Photoperiod experiment. First detection of (Z)-3-hexenal, (Z)3-hexenol, and (Z)-3-hexenyl acetate occurred at 21, 28, and 35 DAT for the 16-, 12-, and 8-h treatments, respectively (Table 4). There were no differences among individual volatiles at any particular sampling time. No differences were detected between mean total volatile emission rates $\left(\mu \mathrm{g} \cdot \mathrm{h}^{-1} \cdot \mathrm{g}^{-1}\right)$ within any photoperiod treatment. The treatment mean emission rate of $2.09 \mu \mathrm{g} \cdot \mathrm{h}^{-1} \cdot \mathrm{g}^{-1}$ of the 16-h photoperiod treatment was significantly different from the $0.74 \mu \mathrm{g} \cdot \mathrm{h}^{-1} \cdot \mathrm{g}^{-1}$ obtained for the 8 -h treatment. The treatment mean emission rate for the 12 -h treatment was $1.44 \mu \mathrm{g} \cdot \mathrm{h}^{-1} \cdot \mathrm{g}^{-1}$ and was not different from those of the 16- and 8-h treatments.

The mean total volatile emission rates at harvest determined with volatile and biomass data measured from chamber EF7 were not different from those calculated with volatile and biomass data from separate chambers with the same environmental conditions (Table 5). Moreover, no differences were detected among emission rates of any photoperiod treatments at harvest.

The regression slope determined from the log-transformed data plotted as volatiles vs. time for the 16 -h photoperiod experiment was significantly greater than that obtained for the 8-h photoperiod treatment. The regression slope of volatiles vs. time for the $12-\mathrm{h}$ treatment was not different from either the 16- or 8-h treatment. The regression slope for shoot dry weight was not different from

Table 3. Mean total volatile emission rates $\left(\mu \mathrm{g} \cdot \mathrm{h}^{-1} \cdot \mathrm{g}^{-1}\right)$ at harvest [days after transplanting (DAT)] for each photosynthetic photon flux (PPF) level ${ }^{\mathrm{z}}$.

\begin{tabular}{lccc} 
PPF & Harvest & \multicolumn{2}{c}{ Growth chamber } \\
\cline { 2 - 4 }$\left(\mu \mathrm{mol} \cdot \mathrm{m}^{-2} \cdot \mathrm{s}^{-1}\right)$ & $(\mathrm{DAT})$ & $\mathrm{EF}^{\mathrm{y}}$ & $\mathrm{EF} 7 / \mathrm{E} 15^{\mathrm{x}}$ \\
\hline 105 & 35 & $0.020 \pm 0.032 \mathrm{~A}$ & $0.056 \pm 0.036 \mathrm{~A}$ \\
200 & 32 & $1.41 \pm 0.63 \mathrm{~B}$ & $1.14 \pm 0.73 \mathrm{~B}$ \\
360 & 32 & $1.68 \pm 0.99 \mathrm{~B}$ \\
\hline
\end{tabular}

${ }^{\mathrm{z}}$ Rates $\pm 95 \%$ confidence limits.

yBiomass and volatiles were measured on same plants in modified growth chamber model EF7.

${ }^{x}$ Volatile measurements were taken from plants grown in modified growth chamber. Biomass was measured from corresponding plants cultivated under similar environmental conditions in a model E15 growth chamber. 
Table 4. Mean total volatile emission rates $\left(\mu \mathrm{g} \cdot \mathrm{h}^{-1} \cdot \mathrm{g}^{-1}\right)$ sorted by days after transplanting (DAT) and photoperiod ${ }^{\mathrm{z}}$.

\begin{tabular}{lccc}
\hline \hline & & Photoperiod (h) \\
\cline { 2 - 4 } DAT & 16 & 12 & 8 \\
\hline 21 & $3.11 \pm 2.47$ & ND $^{\mathrm{y}}$ & ND \\
28 & $1.49 \pm 1.04$ & $0.96 \pm 1.10$ & ND \\
32 & $1.68 \pm 0.99$ & $2.62 \pm 3.88$ & --- \\
35 & --- & $0.76 \pm 0.40$ & $0.92 \pm 0.52$ \\
42 & -- & --- & $0.46 \pm 0.26$ \\
45 & -- & --- & $0.80 \pm 0.66$ \\
Mean $^{\mathrm{x}}$ & $2.09 \pm 0.95 \mathrm{a}$ & $1.44 \pm 1.34 \mathrm{ab}$ & $0.74 \pm 0.30 \mathrm{~b}$
\end{tabular}

$\overline{{ }^{\mathrm{Z}} \text { Rates } \pm 95 \% \text { confidence limits. Experiments conducted under 16-, 12-, and 8-h photoperiods were terminated at 32, 35, and } 45}$

DAT respectively.

yNo volatiles detected.

${ }^{\mathrm{x}}$ Treatment mean emission rate for each photoperiod.

the slope based on total volatiles for either the 8- or 12-h treatment, but the regression slope for shoot dry weight was significantly lower than the slope based on total volatiles in the 16-h treatment.

Temperature experiment. (Z)-3-hexenal, (Z)-3-hexenol and (Z)-3-hexenyl acetate were detected at 14 DAT for the 28/23C temperature treatment, the earliest of any treatment. Volatiles were first detected at 21 DAT in the $23 / 18 \mathrm{C}$ treatment and at 28 DAT in the $18 / 13 \mathrm{C}$ treatment. There were no differences among individual volatiles. Mean total volatile emission rates $\left(\mu \mathrm{g} \cdot \mathrm{h}^{-1} \cdot \mathrm{g}^{-1}\right)$ were not different between any sampling days within any temperature treatment (Table 6).

Mean total volatile emission rates at harvest were not different among any temperature treatments, regardless of whether the rate was calculated with data from chamber EF7 or with volatile collection and biomass data measured independently in chambers EF7 and E15 (Table 7).

Regression slopes of total volatiles plotted against time did not differ among temperature treatments. At 28/23 and 23/18C, regression slopes of total volatiles were significantly higher than their respective slopes of shoot dry weight. No difference was detected between total volatiles and shoot dry weight regression slopes at 18/13C.

Volatile emissions at constant temperature. At 39 DAT during the $18 / 13 \mathrm{C}$ temperature treatment, the sampling jar temperature was held at $18 \pm 1.5 \mathrm{C}$ at the end of the light period and for the first hour of the dark period. Total volatiles emitted under constant temperature at $39 \mathrm{DAT}$ were not different from those at $35 \mathrm{DAT}$ or 42 DAT when sampling jar temperature decreased $5 \mathrm{C}$ at the beginning of the dark period (Table 8).

Volatile emissions bydamaged lettuce. Although (Z)-3-hexenal, (Z)-3-hexenol, and (Z)-3-hexenyl acetate were only detected immediately after the end of the light period under normal sampling conditions, damaged lettuce emitted these compounds regardless of whether the damage was inflicted during the light or the dark period. The rate of volatile release during the $0.5 \mathrm{~h}$ interval after damage was inflicted was of the same order of magnitude as that from undamaged lettuce (grown under the same conditions) during the first $0.5 \mathrm{~h}$ of the dark period.

Lettuce growth rate comparison between chambers. The mean relative growth rates for shoot dry weight for each chamber were calculated as follows (Radford, 1967):

$$
\text { Mean RGR }=\ln \left(W_{2}\right)-\ln \left(W_{1}\right) / t_{2}-t_{1}
$$

where mean RGR $=$ mean relative growth rate $\left(\mathrm{mg} \cdot \mathrm{g}^{-1} \cdot \mathrm{day}^{-1}\right)$, the increase in biomass per unit of biomass present per unit of time. $\ln \left(W_{2}\right)-\ln \left(W_{1}\right)=$ difference between natural logarithms of shoot dry weights at times $t_{2}$ and $t_{1}$ (days), and $t_{2}-t_{1}=$ time interval between harvests (days). In both growth chambers, highest mean RGR was measured at 21 DAT. Thus, the rate of accumulation of dry matter relative to the existing dry matter was highest at this time.

Mean relative growth rates were not significantly different between growth chambers at any specified time (Table 9). No differences were detected between mean RGR values of either chamber from 14 to 21 DAT, or from 28 to 32 DAT. These data indicate that growth trends were not significantly different between chambers EF7 and E15.

\section{Discussion}

Feasibility of using independent volatile and biomass data. Because growth trends were not significantly different between chambers EF7 and E15, volatile emission rates could be calculated from planting to harvest based on measurements of volatiles from chamber EF7 and measurements of biomass from chamber E15. The feasibility of basing mean total volatile emission rates on volatile collection data from chamber EF7 and biomass data from chamber E15 was further justified by comparisons of these rates at harvest. Emission rates derived from volatile and biomass data taken independently from chambers EF7 and E15 were not differ-

Table 5. Mean total volatile emission rates $\left(\mu \mathrm{g} \cdot \mathrm{h}^{-1} \cdot \mathrm{g}^{-1}\right)$ at harvest [days after transplanting (DAT)] for each photoperiod ${ }^{\mathrm{z}}$

\begin{tabular}{|c|c|c|c|}
\hline \multirow{2}{*}{$\begin{array}{l}\text { Photoperiod } \\
\text { (h) }\end{array}$} & \multirow{2}{*}{$\begin{array}{c}\text { Harvest } \\
\text { (DAT) }\end{array}$} & \multicolumn{2}{|c|}{ Growth chamber } \\
\hline & & EF7y & $\mathrm{EF} 7 / \mathrm{E} 15^{\mathrm{x}}$ \\
\hline 8 & 45 & $0.88 \pm 1.02$ & $0.80 \pm 0.66$ \\
\hline 12 & 35 & $0.60 \pm 0.24$ & $0.76 \pm 0.40$ \\
\hline 16 & 32 & $1.42 \pm 0.82$ & $1.68 \pm 1.00$ \\
\hline
\end{tabular}

${ }^{\mathrm{z}}$ Rates $\pm 95 \%$ confidence limits.

${ }^{y}$ Biomass and volatiles were measured on same plants in modified growth chamber model EF7.

${ }^{x}$ Volatile measurements were taken from plants grown in modified growth chamber. Biomass was measured from corresponding plants cultivated under similar environmental conditions in a model E15 growth chamber. 
Table 6. Mean total volatile emission rates $\left(\mu \mathrm{g} \cdot \mathrm{h}^{-1} \cdot \mathrm{g}^{-1}\right)$ sorted by days after transplanting (DAT) and temperature .

\begin{tabular}{lccc}
\hline \hline & & Light-dark temp $\left({ }^{\circ} \mathrm{C}\right)$ & \\
\cline { 2 - 4 } DAT & $28 / 23$ & $23 / 18$ & $18 / 13$ \\
\hline 14 & $4.76 \pm 5.34$ & $\mathrm{ND}^{\mathrm{y}}$ & ND \\
21 & $6.36 \pm 5.56$ & $3.12 \pm 2.48$ & ND \\
28 & $1.06 \pm 0.78$ & $1.48 \pm 1.04$ & $1.60 \pm 1.16$ \\
32 & -- & $1.68 \pm 1.00$ & --- \\
35 & --- & --- & $2.52 \pm 1.82$ \\
42 & -- & -- & $1.58 \pm 1.14$ \\
Mean $^{\mathrm{x}}$ & $4.06 \pm 2.58$ & $2.09 \pm 0.95$ & $1.90 \pm 0.80$
\end{tabular}

${ }_{\mathrm{Z}}$ Rates $\pm 95 \%$ confidence limits. Experiments conducted under 28/23C, $23 / 18 \mathrm{C}$, and 18/13C temperature regimes were terminated at 28,32 , and 42 DAT respectively.

y No volatiles detected.

${ }^{\mathrm{x}}$ Treatment mean emission rate for each temperature regime.

ent from rates based on biomass data measured solely in chamber E15 under equivalent environmental conditions (Tables 3, 5, and 7). The greater part of the variability of the emission rates is attributable to the variability of the volatile collection data, not the variability of the shoot dry weight.

Volatile emissions during plant maturation. No differences were detected between the mean total volatile emission rates $\left(\mu \mathrm{g} \cdot \mathrm{h}^{-1} \cdot \mathrm{g}^{-1}\right)$ at different sampling times within any treatment except for the final sampling day of lettuce cultivated under $105 \mu \mathrm{mol} \cdot \mathrm{m}^{-2} \cdot \mathrm{s}^{-1}$. In contrast, young, expanding leaves of tomato produced highest levels of (E)-2-hexenal and hexanal (Hamilton-Kemp et al., 1992). Ethylene evolution from kidney bean plants (Phaseolus vulgaris L.) was highest during the rapid expansion phase (RecaldeManrique and Díaz-Miguel, 1981; Roberts and Osborne, 1981).

The finding in this study that the emission rates of lettuce volatiles usually did not differ within treatments may indicate that periods of rapid metabolic activity in lettuce are not generally correlated with the production of $\mathrm{C}_{6}$ compounds as they seem to be with ethylene. A second interpretation of this result is that the variability of the data may have obscured the detection of true differences. Plant volatiles are frequently measured by removing leaves or other plant tissue (as was done in the ethylene studies mentioned above) and enclosing them in a small glassware system with tightly controlled inlet air flow and sampling rates. The choice to sample severed or macerated plant tissue for volatile compounds may enable greater precision in quantification, but often introduces the undesirable influences of uncontrolled conditions of temperature and light as well as the direct effects of physical damage, known to alter volatile emissions (Heath et al., 1992).

The sampling system used in this study was relatively noninvasive and nondestructive. Wide variability seems to be present in many plant volatile collection systems. Juuti et al. (1990), for example, reported that at any given temperature, monoterpene emissions from Monterey pine (Pinus radiata D.
Don) varied by a factor of two about the mean, a result that they ascribed to the inherent variability of the plants' emissions.

For the PPF and photoperiod experiments, regression slopes of total volatiles plotted against time generally increased when corresponding regression slopes of shoot dry weight increased, indicating a general trend that higher levels of volatiles were produced as biomass accumulated. No differences were detected among slopes of volatiles produced under different temperature regimes, but these data were more variable than those of the regression slopes of shoot dry weights, which were significantly higher at higher temperatures.

Regression slopes of total volatiles predicted the emission of volatiles earlier in each treatment than were actually detected. In some cases, levels of these predicted emissions were within the range of gas chromatographic detection, and it was surprising that none were found. It is possible that there was insufficient biomass to emit volatiles at levels that could be detected, but future research should also investigate the possibility that when expressed on a dry weight basis, volatile emissions from lettuce are relatively low until the plants enter the exponential phase of growth.

Environmental effects on volatile emissions. The biosynthesis of (Z)-3-hexenal, (Z)-3-hexenol, and (Z)-3-hexenyl acetate occurs in green leaves by the lipoxygenase pathway (Anderson, 1989; Loughrin et al., 1990). Linolenic acid is liberated by the hydrolysis of lipids by lipid acyl hydrolase, and subsequently undergoes hydroperoxygenation by lipoxygenase (LOX). The resulting product, hydroperoxylinolenic acid, is cleaved by hydroperoxide lyase (HL) into (Z)-3-hexenal and 12-oxo-(Z)-9-dodecenoic acid. (Z)3-hexenal is reduced to $(Z)-3$-hexenol by alcohol dehydrogenase $(\mathrm{ADH})$ which then is esterified to $(\mathrm{Z})$-3-hexenyl acetate (Hatanaka et al., 1987; Anderson, 1989).

The activity of the $\mathrm{C}_{6}$-aldehyde-forming enzyme system in lettuce was among the lowest of nearly 40 species examined (Hatanaka et al., 1978; Hatanaka et al., 1987), and LOX activity in

Table 7. Mean total volatile emission rates $\left(\mu \mathrm{g} \cdot \mathrm{h}^{-1} \cdot \mathrm{g}^{-1}\right)$ at harvest [days after transplanting (DAT)] for each temperature ${ }^{\mathrm{z}}$.

\begin{tabular}{lccc}
\hline \hline $\begin{array}{l}\text { Light-dark } \\
\text { temp }\end{array}$ & Harvest & \multicolumn{2}{c}{ Growth chamber } \\
\cline { 2 - 3 }$\left({ }^{\circ} \mathrm{C}\right)$ & (DAT) & EF7 & EF7/E15 \\
\hline $18 / 13$ & 42 & $1.14 \pm 0.72$ & $1.58 \pm 1.14$ \\
$23 / 18$ & 32 & $1.42 \pm 0.82$ & $1.68 \pm 0.99$ \\
$28 / 23$ & 28 & $0.82 \pm 0.90$ & $1.06 \pm 0.78$
\end{tabular}

${ }^{\mathrm{z}}$ Rates $\pm 95 \%$ confidence limits.

yBiomass and volatiles were measured on same plants in modified growth chamber model EF7.

${ }^{x}$ Volatile measurements were taken from plants grown in modified growth chamber. Biomass was measured from corresponding plants cultivated under similar environmental conditions in a model E15 growth chamber. 
Table 8. Mean volatiles per plant (ng) emitted at onset of dark period at constant temperature [39 days after transplanting (DAT)] and during normal $5 \mathrm{C}$ decrease (35 and $42 \mathrm{DAT}^{\mathrm{z}}$.

\begin{tabular}{lccr}
\hline \hline & & DAT & \\
\cline { 2 - 4 } Compound & 35 & $726 \pm 433$ & 42 \\
\hline (Z)-3-hexenal & $712 \pm 230$ & $713 \pm 146$ & $1196 \pm 618$ \\
(Z)-3-hexenol & $604 \pm 182$ & $1240 \pm 44$ & $1287 \pm 690$ \\
(Z)-3-hexenyl acetate & $974 \pm 445$ & $2679 \pm 603$ & $1993 \pm 1144$ \\
Total & $2290 \pm 829$ & $4476 \pm 2387$ \\
\hline
\end{tabular}

${ }^{\mathrm{z}}$ Mean volatiles per plant \pm standard deviation.

yTemperature in sampling jar was maintained at $18 \pm 1.5 \mathrm{C}$.

particular was low in lettuce (Sekiya et al., 1983a). Based on a total of $6 \mathrm{~h}$ of volatile collections, Arey et al. (1991) measured mean emission rates for (Z)-3-hexenol and (Z)-3-hexenyl acetate combined ranging from a low of $0.25 \mu \mathrm{g} \cdot \mathrm{h}^{-1} \cdot \mathrm{g}^{-1}$ (cotton) to a high of 4.2 $\mu \mathrm{g} \cdot \mathrm{h}^{-1} \cdot \mathrm{g}^{-1}$ [peach, Prunus persica L. (Halford)]. When the treatment mean total emission rates for the present study were converted to rates based on the $30 \mathrm{~min}$ during which the volatiles were detected, the lowest obtained was $0.21 \mu \mathrm{g} \cdot \mathrm{h}^{-1} \cdot \mathrm{g}^{-1}\left(105 \mu \mathrm{mol} \cdot \mathrm{m}^{-2} \cdot \mathrm{s}^{-1}\right)$ and the highest rate was $4.1 \mu \mathrm{g} \cdot \mathrm{h}^{-1} \cdot \mathrm{g}^{-1}(28 / 23 \mathrm{C})$. These rates are comparable to those reported for other crops by Arey et al. (1991), but the emissions from lettuce occurred only within the first $30 \mathrm{~min}$ of each dark period. No references to volatile emission rates from lettuce were found in the published literature.

The finding that (Z)-3-hexenal, (Z)-3-hexenol, and (Z)-3hexenyl acetate were emitted within a $30-$ min period of a diurnal cycle may be exploited in a closed environment. In a CELSS system, for example, the results of this study suggest that air purification systems would only need to be activated for a short time every $24 \mathrm{~h}$ for a lettuce crop.

PPF and photoperiod total mean emission rates $\left(\mu \mathrm{g} \cdot \mathrm{h}^{-1} \cdot \mathrm{g}^{-1}\right)$ were highest at highest levels of PPF and photoperiod, but there were no differences for temperature. Because PPF and photoperiod are easily adjusted in a CELSS environment, the operators of a CELSS system could manage emission rates from lettuce by controlling PPF and photoperiod. Future research should investigate the effects of a gradual reduction in light during the light-dark transition.

The higher emission rates produced under high PPF and long photoperiod suggest increased activity of the enzyme system that produces $\mathrm{C}_{6}$ lettuce volatiles at high levels of PPF and photoperiod. LOX activity varies seasonally in most plants (Hatanaka et al., 1978). In young tea (Thea sinensis L.) leaves, activity of the enzyme system producing (Z)-3-hexenal was highest in summer, but showed no activity in winter (Sekiya et al., 1977). Enzyme activity reached a maximum in July and August when solar radiation and temperature were at highest levels. Below 10C, enzyme activity almost disappeared (Sekiya et al., 1983a). Among 37 plant species investigated, including lettuce, activity of (Z)-3hexenal formation in leaves increased from April to July, and decreased in the fall, approximately following seasonal changes in solar radiation and temperature; the specific factors affecting $(\mathrm{Z})$ 3-hexenal formation were not established (Hatanaka et al., 1987).

The enzyme system that synthesizes $\mathrm{C}_{6}$ aldehydes was located in the chloroplast lamellae of green leaves of about 40 plant species sampled (Hatanaka et al., 1978, 1987). The higher mean total volatile emission rates associated with high PPF and long photoperiod may be traced to light-induced changes in chloroplasts. Although fatty acid composition in lettuce did not change in response to irradiance or photoperiod, under high-light conditions, more chloroplasts were present per gram fresh weight and per square centimeter leaf area, and contained less chlorophyll (80 $\left.\mathrm{W} \cdot \mathrm{m}^{-2}\right)$ (Davies et al., 1991).
Sekiya et al. (1983a) reported a positive correlation between HL activity and chlorophyll content in the green leaves of various plants, but LOX activity seemed to affect the production of $\mathrm{C}_{6}$ aldehydes. LOX activity of cultured green alfalfa cells is lightdependent, but HL activity is only slightly light-dependent (Sekiya et al., 1983b). Sekiya et al. (1984) demonstrated that LOX activity is higher at higher temperatures in tea leaves, and ADH activity was low at high temperature. This suggests a relatively more rapid conversion of (Z)-3-hexenal to (Z)-3-hexenol at low temperatures.

Environmental stimulus of volatile emissions. Relative humidity seemed not to be a factor in volatile emissions from lettuce. Purified air entering the sampling jar had low relative humidity (15\% to $30 \%$ ) because moisture was condensed out of the airstream passing through the coil immersed in ice water. As the lettuce plants increased in size, the relative humidity in the jar increased to between $50 \%$ and $60 \%$. In spite of the increasing relative humidity in the jar as the plants matured, there were no differences detected between the mean total volatile emission rates $\left(\mu \mathrm{g} \cdot \mathrm{h}^{-1} \cdot \mathrm{g}^{-1}\right)$ at different sampling times within treatments. An exception was at 32 DAT and 35 DAT for lettuce cultivated under $105 \mu \mathrm{mol} \cdot \mathrm{m}^{-2} \cdot \mathrm{s}^{-1}$, but the relative humidity readings were similar at these two times.

During the first $30 \mathrm{~min}$ of the dark period when volatiles were detected, the growth chamber and sampling jar temperature decreased $5 \mathrm{C}$. The determination was made that volatiles were emitted in similar quantities when temperature was held constant during this 30-min period (Table 8). The effect of reducing the temperature in the sampling jar by $5 \mathrm{C}$ during the final $30 \mathrm{~min}$ of the light period also was measured. The copper coil carrying air into the sampling jar was submersed in an acetone-dry ice slurry and the air flow was adjusted to achieve the desired 5C decrease. No

Table 9. Mean relative growth rate (RGR) $\left(\mathrm{mg} \cdot \mathrm{g}^{-1} \cdot \mathrm{day}^{-1}\right)$ determined from shoot dry weight in each of two growth chambers at specified days after transplanting (DAT).

\begin{tabular}{lccc}
\hline \hline Mean RGR & & Chamber $^{\mathrm{y}}$ & Sample size \\
\hline $0.30 \mathrm{abc}$ & DAT & EF7 & 5 \\
$0.30 \mathrm{abc}$ & 14 & E15 & 9 \\
$0.33 \mathrm{ab}$ & 14 & EF7 & 5 \\
$0.34 \mathrm{a}$ & 21 & E15 & 9 \\
$0.26 \mathrm{bcd}$ & 21 & EF7 & 4 \\
$0.25 \mathrm{~cd}$ & 28 & E15 & 8 \\
$0.22 \mathrm{~d}$ & 28 & EF7 & 4 \\
$0.21 \mathrm{~d}$ & 32 & E15 & 8
\end{tabular}

${ }^{\mathrm{z}}$ Mean relative growth rate. Means with the same letter are not different based on Duncan multiple range test at $\alpha=0.05$.

${ }^{y}$ E15 refers to growth chamber used for all growth rate experiments. EF7 refers to modified growth chamber normally used for volatile collection experiments. 
volatiles were detected during this procedure. These results are evidence that the light-to-dark transition is the principal factor triggering the emission of volatiles at the beginning of the dark period. A study that examines how volatile emissions are affected by a gradual light-to-dark transition may provide additional insight into the factors that initiate the release of volatiles.

When exposed to continuous light for a 72-h period beginning at 32 DAT, no volatiles were detected until the dark cycle was restored. This result suggests that the emission of $\mathrm{C}_{6}$ compounds from lettuce at the onset of the dark period is not a circadian rhythm. Periodic emissions that are circadian in nature would continue, at least for sometime, under constant illumination (Johnson and Hastings, 1986). Future research should investigate whether the plant emissions in a CELSS could be reduced by growing plants under continuous light from planting to harvest.

The emission of (Z)-3-hexenal, (Z)-3-hexenol, and (Z)-3hexenyl acetate in response to mechanical damage to plants has been reported previously. Increased emissions of (Z)-3-hexenol and (Z)-3-hexenyl acetate were detected from agricultural crops subjected to rough handling (Winer et al., 1992). Lipoxygenase pathway products such as (Z)-3-hexen-1-ol, hexanol, (E)-2-hexenal, (Z)-3-hexenal, and hexanal commonly evolve from macerated green plant material (Buttery, 1981).

(Z)-3-hexenal and (Z)-3-hexenol exhibit antifungal effects against Botrytiscinerea, Rhizoctonia solani, Fusarium oxysporum, Didymella lycopersici, and Cladosporium fulvum (Urbasch, 1984). The release of these compounds in response to mechanical stress may function as a type of defense mechanism. Other structurally similar $\mathrm{C}_{6}$ compounds have antibacterial properties (Deng et al., 1993).

(Z)-3-hexenal, (Z)-3-hexenol, and (Z)-3-hexenyl acetate may be of concern in a closed system such as CELSS under development by NASA. In Earth's atmosphere, (Z)-3-hexenol and (Z)-3-hexenyl acetate have tropospheric lifetimes of 1-3 h. They react with $\mathrm{OH}$ and $\mathrm{NO}_{3}$ radicals and ozone to produce propanal, 3-hydroxypropanal, and 3-acetoxypropanal. Subsequent chemical conversions can lead toperoxypropionyl nitrate $(\mathrm{PPN})$ and peroxyacetylnitrate (PAN)(Arey et al., 1991). The fate of (Z)-3-hexenol and (Z)-3-hexenyl acetate should be investigated in a CELSS.

Volatile emission rates are influenced by the resistance within the diffusive pathway from biosynthetic sites to the atmosphere. The physical distance and path traveled by (Z)-3-hexenal, (Z)-3hexenol, and (Z)-3-hexenyl acetate are factors that could affect emissions. The physical path has not been clearly elucidated but probably would involve diffusion through cells, intercellular air spaces, passage through the stomata, and perhaps through the cuticle as well.

Significance of results. In this study, plant volatiles were measured nondestructively, from planting to harvest, from lettuce grown under controlled environmental conditions. In other studies we found in the literature, volatiles were measured from cut or macerated plant tissue, volatile emissions were not measured over several diurnal cycles, or few or no environmental conditions were controlled.

This study demonstrated that volatile emissions from lettuce can be regulated by adjusting PPF and photoperiod. In a closed environment such as that in a CELSS, air quality is a concern. The results of this investigation suggest that environmental control of volatile emissions could be a useful method for restricting contaminants below harmful levels. Activation of air purification systems during the light-to-dark transition would be a second strategy to control air quality. Ultimately, management of air quality must be based on future research that examines the fate and effects of plant volatiles in a completely closed environment.

\section{Literature Cited}

Agresti, A. 1990. Categorical data analysis. Wiley, New York.

Anderson, J.M. 1989. Membrane-derived fatty acids as precursors to second messengers, p. 181-212. In: W.F. Boss and D.J. Morré (eds.). Second messengers in plant growth and development. Alan R. Liss, New York.

Arey, J., A.M. Winer, R. Atkinson, S.M. Aschmann, W.D. Long, and C.L. Morrison. 1991. The emission of (Z)-3-hexen-1-ol,(Z)-3-hexenylacetate, and other oxygenated hydrocarbons from agricultural species. Atmos. Environ. 25:1063-1075.

Buttery, R.G. 1981. Vegetable and fruit flavors, p. 175-216. In: R. Teranishi and R.A. Flath (eds.). Flavor research: Recent advances. Marcel Dekker, New York.

Buttery, R.G. and L.C. Ling. 1993. Volatile components of tomato fruit and plant parts: relationship and biogenesis, p. 23-34. In: R. Teranishi, R.G. Buttery, and H. Sugisawa (eds.). Bioactive volatile compounds from plants. Amer. Chem. Soc., Washington, D.C.

Charron, C.S., D.J. Cantliffe, R.M. Wheeler, A. Manukian, and R.R. Heath. 1996. A system and methodology for measuring volatile organic compounds produced by hydroponic lettuce in a controlled environment. J. Amer. Soc. Hort. Sci. 121:483-487.

Davies, H., B.R. Jordan, and J.L. Harwood. 1991. Changes in acyl-lipid, protein, and chlorophyll content of lettuce and tomato chloroplasts during acclimation to changes in irradiance. Plant Physiol. Biochem. 29:281-288

Deng, W., T.R. Hamilton-Kemp, M.T. Nielsen, R.A. Andersen, G.B. Collins, and D.F. Hildebrand. 1993. Effects of six-carbon aldehydes and alcohols on bacterial proliferation. J. Agr. Food Chem. 41:506-510.

Hamilton-Kemp, T.R., C.T. McCracken, J.H. Loughrin, R.A. Andersen, and D.F. Hildebrand. 1992. Effects of some natural volatile compounds on the pathogenic fungi Alternaria alternata and Botrytis cinerea. J. Chem. Ecol. 18:1083-1091.

Hatanaka, A., T. Kajiwara, and J. Sekiya. 1987. Biosynthetic pathway for $\mathrm{C}_{6}$-aldehydes formation from linolenic acid in green leaves. Chem. Phys. Lipids 44:341-361.

Hatanaka, A., J. Sekiya, and T. Kajiwara. 1978. Distribution of an enzyme system producing cis-3-hexenal and n-hexenal from linolenic and linoleic acids in some plants. Phytochemistry 17:869-872.

Heath, R.H., P.J. Landolt, B. Deuben, and B. Lenczewski. 1992. Identification of floral compounds of night-blooming jessamine attractive to cabbage looper moths. Environ. Entomol. 21:854-859.

Isidorov, V.A., I.G. Zenkevich, and B.V. Ioffe. 1985. Volatile organic compounds in the atmosphere of forests. Atmos. Environ. 19:1-8.

Johnson, C.H. and J.W. Hastings. 1986. The elusive mechanism of the circadian clock. Amer. Sci. 74:29-36.

Juuti, S., J. Arey, and R. Atkinson. 1990. Monoterpene emission rate measurements from a Monterey pine. J. Geophys. Res. 95:7515-7519.

Loughrin, J.H., T.R. Hamilton-Kemp, R.A. Andersen, and D.F. Hildebrand. 1990. Volatiles from flowers of Nicotiana sylvestris, N. otophora and Malus ¥domestica: Headspace component and day/night changes in their relative concentrations. Phytochemistry 29:2473-2477.

Miller, R. 1981. Survival analysis. Wiley, New York.

Radford, P.J. 1967. Growth rate formulae-Their use and abuse. Crop Sci. 7:171-175.

Recalde-Manrique, L. and M. Díaz-Miguel. 1981. Evolution of ethylene by sulphur dust addition. Physiol. Plant. 53:462-467.

Roberts, J.A. and D.J. Osborne. 1981. Auxin and the control of ethylene production during the development and senescence of leaves and fruits. J. Expt. Bot. 32:875-887.

Sekiya, J., T. Kajiwara, and A. Hatanaka. 1977. Seasonal changes of the enzyme system producing cis-3-hexenal and n-hexenal from linolenic and linoleic acids in tea leaves. Plant Cell Physiol. 18:283-286.

Sekiya, J., T. Kajiwara, and A. Hatanaka. 1984. Seasonal changes in activities of enzymes responsible for the formation of $\mathrm{C}_{6}$-aldehydes and $\mathrm{C}_{6}$-alcohols in tea leaves, and the effects of environmental temperatures on the enzyme activities. Plant Cell Physiol. 25:269-280.

Sekiya, J., T. Kajiwara, K. Munechika, and A. Hatanaka. 1983a. Distribution of lipoxygenase and hydroperoxide lyase in the leaves of various plant species. Phytochemistry 22:1867-1869.

Sekiya, J., K. Munechika, and A. Hatanaka. 1983b. Further characterization of $\mathrm{C}_{6}$-aldehyde-forming system in alfalfa cells cultured in vitro. Agr. Biol. Chem. 47:1647-1648.

Winer, A.M., J. Arey, R. Atkinson, S.M. Aschmann, W.D. Long, C.L. Morrison, and D.M. Olszyk. 1992. Emission rates of organics from vegetation found in California's Central Valley. Atmos. Environ. 26A:2647-2659. 